\title{
En torno a la disyuntiva décima/subsidio en Castilla y la Corona de Aragón durante la Baja Edad Media*
}

\author{
Jordi Morelló Baget ${ }^{1}$ \\ IMF-CSIC (Barcelona) \\ jmorellobaget@gmail.com
}

RESUMEN: En este artículo, llevamos a cabo una sucinta revisión diacrónica y comparativa del largo proceso que, tanto en la Corona de Aragón como en Castilla, fue discurriendo en torno a dos formas de imposición fiscal extraordinaria (décimas y subsidios), que podemos tomar como representativas de un importante trasvase de renta eclesiástica a favor de la incipiente fiscalidad estatal. Siguiendo sucesivas fases cronológicas, desde el siglo XIII hasta la época de los Reyes Católicos, intentamos ver la frecuencia con la que ambas monarquías hicieron uso de ambos tipos de prestación, con o sin autorización papal, los diferentes motivos aducidos en cada caso, así como otras cuestiones relativas al consentimiento del clero y al papel de las asambleas eclesiásticas en la gestión de esas cargas. A pesar de ciertas divergencias y de las distintas dinámicas desarrolladas en cada reino, es obvio que ambas modalidades de contribución clerical condujeron al establecimiento cada vez más regular de impuestos sobre la renta, en tanto que constitutivos de una fiscalidad sustentada

\footnotetext{
${ }^{*}$ Este trabajo se ha efectuado en el marco del proyecto de investigación titulado «Financieros al servicio del poder en la Corona de Aragón (S. XIV-XV): métodos, agentes, redes (HAR2011-24839)» y del Grup consolidat de la Generalitat de Cataluña «Renda feudal i fiscalitat a la Catalunya baixmedieval» (2014 SFG-1154).

Siglas de archivos: Archivo de la Corona de Aragón (ACA), Archivo de la Catedral de Barcelona (ACB), Archivo Capitular de la Seo de Zaragoza (ACZ), Archivo Diocesano de Barcelona (ADB), Archivo Diocesano de Girona (ADG), Archivo Histórico Archidiocesano de Tarragona (AHAT), C (Cancillería), MR (Maestre Racional), RC (Registra communium), RN (Registra negotiorum) y RP (Real Patrimonio). Abreviaturas: fl. $=$ florines $/$ fl.a. $=$ florines de Aragón; lb. = libras (barc. = barcelonesas); s. = sueldos.

1 ORCID iD: http://orcid.org/0000-0001-6740-2088. 
en base a la tasación de los beneficios eclesiásticos. Este artículo se ha elaborado a partir de una revisión selectiva de la producción bibliográfica y de la consulta, por lo que concierne a la Corona de Aragón, de fuentes archivísticas de primera mano.

Palabras Clave: Fiscalidad; Castilla; Corona de Aragón; décimas; subsidios eclesiásticos.

On the tithes/subsidies dilemma in Castile and the Crown of Aragón in the Late Middle Ages

ABSTRACT: This work is a diachronic and comparative analysis of the lengthy process in the Crown of Aragon and Castile, involving two forms of extraordinary taxation (tithes and subsidies), which can be considered representative of a major transfer of ecclesiastical income in favour of the emerging tax state. We follow successive chronological phases from the thirteenth century to the reign of the Catholic Monarchs, to ascertain how often the monarchy made use of each type of levy -imposed with or without papal authorization - the different reasons given in each case, and other issues concerning the consent of the clergy and the role of church assemblies in the management of these payments. Despite the divergences and different dynamics that developed in each kingdom, it is clear that both forms of clerical contribution led to the imposition of more regular income taxes, while establishing a fiscality based on the taxation of ecclesiastical gains. The work has been prepared from a selective review of bibliographical output and the consultation of primary sources relating to the Crown of Aragon

KEY WORDS: Fiscality; taxation; Castile; Crown of Aragon; tithes; ecclesiastical subsidies.

CÓMO CITAR ESTE ARTÍCULO/CITATION: Morelló Baget, Jordi, «En torno a la disyuntiva décima/subsidio en Castilla y la Corona de Aragón durante la Baja Edad Media», Hispania, 77/257 (Madrid, 2017): 643-671. doi: 103989/hispania.2017.017

Durante la Baja Edad Media, las monarquías seculares contaron con distintas formas de contribución extraordinaria de la Iglesia. Según M.A. Ladero, hay que distinguir entre las contribuciones o «subsidios» que el clero otorgaba al rey y las «décimas» sobre las rentas eclesiásticas que éste cobraba previa autorización pontificia ${ }^{2}$. Como veremos aquí, esa distinción no puede ser tomada a rajatabla, pues también hubo subsidios otorgados por el papado al margen de poder contar, o no, con la conformidad del clero del reino. Por otra parte, también los subsidios pasaron a ser recaudados vía establecimiento de

2 LADERO QUESADA, 1999: 136. 
gravámenes proporcionales sobre las rentas de los eclesiásticos en base a las tasas decimales, razón por la cual no resulta inapropiado considerar a esos subsidios como verdaderos impuestos, del mismo modo que tampoco resulta descabellado tomar al impuesto de la décima como una forma específica de subsidio en función de la finalidad que se le daba.

En otro orden de cosas, también es necesario distinguir, siempre que sea posible, entre aquellas demandas regias que debían ser repercutidas sobre los habitantes de los señoríos eclesiásticos, como solía ser el caso de los servicios o donativos aprobados en cortes $^{3}$, de aquellas otras que afectaron directamente al clero, o sea, considerando a este como contribuyente o sujeto fiscal ${ }^{4}$. Independientemente del vocablo utilizado en cada ocasión ${ }^{5}$, aquí me interesa rastrear cualquier tipo de prestación que implicara o se fundamentase en una tasación de las rentas eclesiásticas en su conjunto, a diferenciar, por tanto, del trasvase de una renta en concreto como también de una simple demanda de dinero ${ }^{6}$.

La petición de subsidios llevaba implícita una negociación, o bien con el papado o bien con el conjunto de prelados del reino, al margen de otras demandas realizadas a los eclesiásticos individualmente o por separado ${ }^{7}$. En un caso, se trataba de obtener la correspondiente autorización papal; en el otro, se apelaba al propio clero, como parte afectada, para que diera su consentimiento formal a la prestación de la ayuda, pero ambas vías no estaban reñidas. Tratándose de subsidios negociados con el clero, no solo se daba la posibilidad de modificar - a la baja - el monto que debía entregarse a la monarquía, sino también de condicionar su aceptación a una serie de contraprestaciones o limitaciones. El marco más adecuado para llevar a cabo esas negociaciones fueron, por lo menos en la Corona de Aragón, las propias

3 Se puede considerar que los obispos y demás eclesiásticos miembros de la élite política del reino acudían a esas asambleas más como titulares de jurisdicciones y señores de vasallos que como jerarcas de sus respectivas diócesis.

4 Ciertamente, algunas veces se habla de contribuciones extraordinarias de prelados sin poder aclarar si se trataba de servicios de cortes o de prestaciones que afectaban directamente al clero. El problema, en cualquier caso, se plantea sobre todo para una primera época, y más que nada por lo que respecta a Castilla, donde las fuentes manejadas por los historiadores suelen ser menos explícitas.

5 Tanto en la Corona de Aragón como en Castilla, acabó prevaleciendo el término subsidio frente a otros utilizados más esporádicamente, tales como «ayuda», «auxilio» o «subvención»».

6 Ciertamente, las noticias recopiladas no siempre ofrecen pistas suficientes para poder conocer todo lo que rodea al hecho fiscal, y solo a medida que vamos avanzando en el tiempo podemos obtener datos más esclarecedores.

7 Dado que la negociación requería un tiempo de espera, algunos monarcas tiraron por el camino de en medio haciendo uso de la fuerza o de la coacción para obtener sumas de dinero de forma rápida, como Pedro I de Castilla cuando exigió cantidades extraordinarias sobre algunas iglesias del reino, lo que contribuiría a su calificación como tirano de que se valieron sus enemigos en la propaganda de la guerra civil. LADERO QUESADA, 1993: 211-212. 
asambleas del clero, esto es, los concilios provinciales. Por otra parte, si dar subsidios al rey debía ser considerado - en principio-, como un acto voluntario, el pago de la décima no lo era en absoluto, en tanto que se trataba de una contribución impuesta al clero por el papa —en su condición de jefe máximo de la Iglesia-, de acuerdo con los preceptos recogidos en las correspondientes bulas de concesión.

No podemos obviar, por otra parte, que subsidios y décimas constituyen dos formas de transferencia de renta eclesiástica entre otras muchas que vinieron siendo utilizadas por las monarquías ${ }^{8}$. Pero así como hubo rentas intervenidas de buen principio por el aparato fiscal de la corona ${ }^{9}$, la gestión y recaudación de los subsidios estuvo siempre en manos del propio clero - en el caso de las décimas, de los colectores eclesiásticos nombrados por el papado- - lo que no excluye un cierto grado de intervención de los oficiales regios en el control de las sumas transferidas al fisco. Sin duda, ambas formas de contribución extraordinaria pudieron llegar a representar un importante trasvase de renta eclesiástica a favor de la fiscalidad «estatal» en sus primeras fases de desarrollo, sobre todo en aquellos periodos en los que tales prestaciones casi llegaron a regularizarse.

El propósito de este artículo es llevar a cabo un análisis diacrónico y comparativo del largo proceso que, tanto en la Corona de Aragón como en Castilla, fue discurriendo en torno a esas dos formas de imposición fiscal extraordinaria. Al respecto, iré abordando sucesivas etapas cronológicas, desde el siglo XIII hasta los albores del XVI, para ver la frecuencia con la que ambas monarquías hicieron uso de subsidios y décimas, con o sin expresa autorización papal, los diferentes motivos aducidos, así como otras cuestiones no menos importantes relativas al consentimiento del clero y al papel de las asambleas eclesiásticas en la gestión de esas cargas. Asimismo, veremos hasta qué punto pudieron darse dinámicas divergentes según pongamos el foco en el ámbito castellano o en el aragonés. Como es obvio, el tema en sí sería inabarcable, por lo que me limitaré a destacar algunos aspectos de tal evolución, restringiendo las citas bibliográficas a las estrictamente necesarias.

8 En los últimos tiempos se ha insistido mucho en la cuestión de la transferencia de renta eclesiástica a favor de las monarquías. Como apuntaba hace poco Ladero: «Es preciso conocer lo mejor posible la fundamental participación de la Iglesia en la transferencia o aportación de recursos económicos a la fiscalidad real», dando a entender, implícitamente, que aún no se ha avanzado lo suficiente en esa línea. LADERO QUESADA, 2015: 37-38.

9 Este es el caso de las tercias reales (2/9 partes del diezmo eclesiástico), o de su equivalente en la Corona de Aragón, el terç-delme del reino de Valencia, en cuanto que pasaron a ser fuentes de renta ordinaria de las respectivas haciendas regias, en el caso castellano ya en época tardía, esto es, en virtud de la concesión papal a perpetuidad obtenida en 1421 en favor de Juan II. 


\section{En el origen de todo, la Guerra Santa. Primeras contribuciones DEL CLERO}

Como es bien sabido, la guerra se convirtió en el principal motor del desarrollo del estado fiscal, ya desde sus inicios ${ }^{10}$. En ese sentido, no se puede obviar que el papado tuvo una parte de responsabilidad, concretamente a través del fomento de las cruzadas contra los musulmanes, esto es, a base de instar a los príncipes laicos a implicarse en la organización de distintas expediciones militares a Tierra Santa en defensa de los Santos Lugares. Para financiar esas costosas expediciones, pronto se recurrió al establecimiento de nuevos impuestos, primero un veinteno y luego el llamado «diezmo de Saladino» - en el marco, respectivamente, de la segunda y la tercera gran cruza$\mathrm{da}$-, ambos impuestos creados a instancias de los monarcas capetos ${ }^{11}$. De hecho, la cruzada fue un motivo incorporado por Luis VII de Francia, a raíz de la segunda gran expedición a Tierra Santa, entre las diferentes razones consideradas legítimas, según la costumbre feudal, de las ayudas al señor ${ }^{12}$. Bien es verdad que se trataba de impuestos de carácter general — afectando no únicamente al clero- y que debían ser los propios contribuyentes quienes debían declarar, bajo juramento, el valor de sus bienes o rentas. Es de suponer que los clérigos tendrían que hacerlo de sus rentas beneficiales; la época coincide, además, con la generalización del sistema beneficial en la Iglesia de Occidente. Con todo, habría que considerar al papa Inocencio III como principal responsable de la generalización de esos impuestos proporcionales a raíz de la exacción establecida en $1199^{13}$, a la que siguieron muchas otras a lo largo del siglo XIII, como subsidios «pro defensione Terrae Sancte». El IV Concilio de Letrán (1215) marcó la norma a seguir al declarar que ningún subsidio podía ser concedido a un rey sino para los gastos de una cruzada y con la autorización del papa. Ahora bien, los monarcas ibéricos trataron de convencer al papado para poder utilizar esos impuestos en sus campañas bélicas contra los musulmanes de Al-Ándalus y sus aliados norteafricanos, sobre todo Castilla, que, como apuntaba Ladero, casi siempre actuó al margen del régimen general ${ }^{14}$.

10 Desde el punto de vista de la historiografía actual, se mantiene la tesis según la cual war is considered the primary engine of state development and this through fiscality. CAROCCI y COLLAVINI, 2014: 148.

11 DE LA MARDIÈRE y CHEVREAU, 2012: 23-28.

12 No está de más recordar los otros tres casos: cuando el primogénito era armado caballero, cuando la hija contraía matrimonio y por el rescate del señor hecho prisionero.

13 De su colecta en la península Ibérica da fe un documento publicado por MANSILLA, 1955: 269-270 (doc. $\left.\mathrm{n}^{\mathrm{o}} 241\right)$.

14 LADERO QUESADA, 1993: 204. De hecho, ya desde Urbano II, la guerra mantenida contra los musulmanes de la Península gozaba de la misma consideración de cruzada que la 
Efectivamente, los reyes castellanos recurrieron en un principio a las «décimas» generales; ya en 1218 el arzobispo de Toledo, Rodrigo Jiménez de Rada, solicitó del papa Honorio III que renunciara en favor de la cruzada occidental a la vigésima impuesta en el citado concilio lateranense - en el marco de la quinta cruzada a Oriente-, pero el papa únicamente autorizó la inversión de la mitad de la exacción que se recaudase en las diócesis de Toledo y Segovia. Como al final resultó que la campaña militar no pudo realizarse, el papa pasó a reclamar al arzobispo el dinero de la vigésima que había ya cobra$\mathrm{do}^{15}$. No obstante, para encontrar una transferencia a favor de la monarquía debemos situarnos en 1265, cuando Clemente IV se avino a obligar al clero castellano a financiar la guerra contra los granadinos, empleando en ella la centésima que debían pagar en ayuda de Tierra Santa, siendo una contribución transformada al cabo de poco tiempo en una décima ${ }^{16}$. De esa décima - la primera propiamente dicha-, se beneficiaron tanto el rey castellano como el aragonés ${ }^{17}$; a partir de entonces, y hasta el siglo XVI, pasaría a ser el único tipo de gravamen autorizado por el papado, en detrimento, pues, de otros gravámenes proporcionales.

Años más tarde, fue el papa Gregorio X quién prometió a Alfonso X la décima sexenal que Castilla debía pagar, como los demás reinos, para Tierra Santa, si renunciaba a sus aspiraciones al trono alemán; pero el motivo final acabó siendo, nuevamente, la guerra contra los musulmanes benimerines. En 1275, el papa puso a disposición del rey castellano la décima de todas las rentas eclesiásticas del reino tal y como había sido concedida en el concilio II de Lyon ${ }^{18}$.

Al margen del proceso evolutivo concerniente a la décimas papales, hubo otras contribuciones del clero a las que también debemos prestar atención. En Castilla, los primeros ejemplos conocidos datan de 1236 - por motivo desconocido- y 1252, para la proyectada campaña de Alfonso X al norte de África, siendo ambos subsidios obtenidos a partir de concesiones pontificias ${ }^{19}$.

llevada a cabo en Oriente, como nos recuerda ARRANZ GUZMÁN, 2006: 262, que también incide en su ideologización como guerra santa o «santa conquista».

15 La causa de la interrupción de la campaña se atribuye a discordias entre los reyes. Véase GOÑI GAZTAMBIDE, 1958: 144-145 y 147-148. LADERO QUESADA, 1993: 203. Algunas referencias a la colecta de ese impuesto papal en las diócesis de la Tarraconense en FREEDMAN, 1994: 37-40.

16 GOÑI GAZTAMBIDE, 1958: 193-194. LINEHAN, 1975: 181.

17 El reino de Portugal no tardaría mucho en incorporarse a ese tipo de concesiones, concretamente en 1268 y 1275, según LADERO QUESADA, 1993: 204.

18 GOÑI GAZTAMBIDE, 1958: 201. LINEHAN, 1975: 186. Recordemos que esa décima fue recogida en Aragón y Navarra con destino a las arcas pontificias, cuya dos últimas anualidades de 1279-1280 conforman las famosas Rationes decimarum que publicó Rius Serra en base a un registro de colecta vaticano.

19 De 1236 es un subsidio ordenado por el papa Gregorio IX para que los obispos hicieran entrega a Fernando III durante tres años de 20.000 áureos procedentes de las rentas 
Respecto de otras contribuciones extraordinarias, como las de 1290 y 1294 - en el marco de la lucha contra los benimerines - , se han dado a conocer los repartos efectuados entre las diferentes sedes episcopales, cabildos catedralicios y monasterios según los niveles de renta que tendrían entonces ${ }^{20}$.

En la Corona de Aragón, la décima impuesta en 1265 tuvo varios precedentes, siendo también resultado de la desviación de impuestos destinados a Tierra Santa (vigésimas), tanto en 1229 —para la empresa de Mallorca-, como en 1248-49 — para dar fin a la conquista de Valencia-. En este caso se trata de dos subsidios consecutivos que fueron aprobados por los prelados de la provincia eclesiástica en los concilios celebrados en Tortosa y Tarragona, y contando con el consentimiento previo del papa Inocencio IV ${ }^{21}$. Naturalmente, no fueron las únicas aportaciones económicas que hizo la Iglesia a las empresas del Conquistador; en ocasiones, encontramos a prelados actuando, según parece, a título personal; así, por ejemplo, en 1234 Jaime I reconocía al arzobispo de Tarragona, Espárago de la Barca, que el servicio que le había hecho en dinero en los inicios de la campaña de conquista de Valencia era, entre otras salvedades, "sola gratia et liberalitate vestra et non ex debito»; tal fórmula o parecida sería una y otra vez invocada en posteriores ayudas del clero a favor de la monarquía. En 1269, cuando la proyectada expedición del mismo monarca a Tierra Santa, el obispo y cabildo de Girona ofrecieron un subsidio gratuito de 10 mil sueldos a cambio de la confirmación de cierto privilegio. En ambos casos se trataba de prestaciones voluntarias, y como tales no podían ser tomadas como precedentes de futuras demandas.

En la Castilla de esa época, las transacciones Monarquía-Iglesia estuvieron supeditadas a condiciones similares, a cambio, unas veces, de la confirmación de los privilegios y libertades del clero - indirectamente, a cambio también de la protección que tenía encomendada la monarquía en favor de la Iglesia-, a cambio, otras veces, de la obtención de determinados favores o promesas de indemnidad. Así, por ejemplo, los obispos aceptaron otorgar la contribución de 1255 a cuenta de la devolución a la Santa Sede de una cantidad debida por Fernando III, sin que en el futuro se tomase por uso y costumbre ordinarios. Una transacción similar tuvo lugar en 1311, cuando Fernando IV prometió,

eclesiásticas de Castilla y León. LADERO QUESADA, 1993: 192 y 203. El siguiente subsidio de 1252 fue concedido al rey sabio por Inocencio IV. LADERO QUESADA, 1993: 204. Por lo que parece, los prelados del reino habrían sido, en ambos casos, meros ejecutores de un mandato papal.

${ }^{20}$ Complementado con otros dos repartos efectuados en 1326. Véase LADERO QUESADA, 1993: 213-216.

21 VINCKE, 1962: 275. LINEHAN, 1975: 106, nota 93. SÁNCHEZ MARTÍNEZ, 2011: 145. 
una vez más, que no se impondrían contribuciones al clero sin el consentimiento previo de los prelados 22 .

En la Corona de Aragón, los sucesores de Jaime I siguieron recabando diferentes ayudas del clero por otros motivos, como fueron las revueltas nobiliarias durante el reinado de Pedro el Grande, las embajadas a la corte pontificia - en 1286 y en 1294-, o para pagar ciertas deudas de Alfonso el Liberal (1292). Con todo, la principal aportación eclesiástica de esta época se vincula con el subsidio que fue exigido, más que solicitado, por Pedro el Grande para hacer frente a la invasión del Principado por parte del poderoso ejército francés, en 1285. El rey comisionó a varios agentes para recoger las cantidades que debían ser consignadas sobre las rentas regias. Quién más debía aportar era el arzobispo de Tarragona con 100.000 sueldos, y siguen los demás prelados, aunque no todos ${ }^{23}$, así como diferentes cargos capitulares - destaca el paborde de Tarragona, con $50.000 \mathrm{~s}$.- - abades y priores de diversos establecimientos eclesiásticos, y un número indeterminado de rectores de parroquias, generalmente por cantidades mucho más modestas — de tan solo $2.000 \mathrm{~s}$. Aparentemente, cada uno sería tasado en función de su riqueza o nivel de rentas, quizás de forma más expedita por lo que atañe al bajo clero. Pese al número de personas implicadas en esta operación —más de 150 , sin contar canónigos y rectores que no quedan individualizados-, no estarían todos. Sea como fuere, constituye un buen ejemplo de participación masiva de la Iglesia en un subsidio o, más bien, préstamo forzoso. Por el momento, no nos consta si hubo devolución de las cantidades tomadas, lo que tampoco es posible saber en relación con otras aportaciones dinerarias realizadas a favor del mismo monarca en forma de subsidio-préstamo y por otros motivos.

Por último, habría que tener en cuenta que otra forma de contribución de las iglesias del reino a las empresas bélicas de la monarquía fue a base de poner a disposición de la misma un cierto número de efectivos y/o de pertrechos. Por descontado, esas prestaciones militares pudieron ser conmutadas, al cabo del tiempo, por su equivalente en moneda ${ }^{24}$.

22 Todos los ejemplos aludidos en LADERO QUESADA, 1993: 210-211. En contraste con la Corona de Aragón, en la Castilla de esta época no parece que las asambleas del clero jugasen ningún rol en la aprobación de los subsidios. Según Linehan, los obispos de Castilla y León estuvieron tan estrechamente identificados con el rey que su único foro común lo representaba la corte real, más bien que el concilio provincial. LINEHAN, 1975: 107.

23 Al obispo de Girona, el rey le pedía un monto tres veces superior al ofrecido años antes de forma voluntaria junto con el cabildo, esto es, 30.000 sueldos; al de Tortosa, 50.000; al de Valencia, 60.000; al de Lleida, 40.000; y al de Vic, 10.000; ACA, C, Memoriales 71/1 y $71 / 2$, ff. 27r-29r. En cambio, echamos en falta las diócesis de Aragón y, por lo que respecta a Cataluña, la de Urgell.

${ }^{24}$ En 1405, con vistas a la reanudación de la guerra con Granada, Enrique III solicitó de la Iglesia que contribuyese al pago de 1.000 lanzas en vez de las 1.500 que tradicionalmente 


\section{Primera MitAd DEL SIGLO XIV: ALTERNANCIA DE DÉCIMAS Y SUBSIDIOS}

Aún por lo que respecta a la décima sexenal decretada en el concilio de Vienne (1312) para Tierra Santa, ambas monarquías seguían con la tónica habitual de intentar sacar provecho para sus empresas particulares ${ }^{25}$. No obstante, la novedad de esta etapa estaría marcada por la obtención de décimas «privativas», es decir, autorizadas por el papado a un monarca en particular. En Castilla, hay registrada la de 1309 - por tres años - y ya en tiempos de Alfonso XI, las de 1317, 1329, 1340 y $1343^{26}$. Todas esas concesiones fueron validadas por pocos años, pese a los intentos regios de obtener concesiones por periodos más amplios ${ }^{27}$.

Para los monarcas aragoneses, la lucha contra los musulmanes continuó siendo un asunto importante, pero cada vez menos frente a otras prioridades relacionadas con su política geoestratégica en el Mediterráneo, sobre todo a raíz de la cesión papal de Cerdeña y Córcega tras los acuerdos de Anagni. Así, al margen de la concesión obtenida de Bonifacio III a finales de 1297 por la cuestión de Sicilia - en el marco de la lucha de Jaime II contra Federico II-, la siguiente décima de 1305 debía ir destinada a la conquista de las dos islas, pero, como tal empresa de momento no se llevó a cabo, acabó siendo reutilizada para la campaña de Almería ${ }^{28}$. Finalmente, a raíz de la ocupación efectiva de Cerdeña, el rey obtuvo, aparte del subsidio de 1322 anotado más abajo, una décima concedida por Juan XXII en 1324, en este caso para poder liquidar los gastos ocasionados por dicha empresa de conquista. La cruzada contra Granada volvió a un primer plano a raíz de la décima que estuvo negociando Alfonso el Benigno, pero fue su sucesor, Pedro el Ceremonioso, quien finalmente la obtuvo para financiar la guerra del Estrecho (1345), siendo la

se venían exigiendo. En la diócesis de Cuenca se procedió al reparto (¿entre el clero de las parroquias?) de los $55.000 \mathrm{mrs}$. que costaría el mantenimiento de 36 lanceros, toda vez que se da a conocer la cantidad que debía aportar el cabildo catedralicio. DÍAZ IBÁÑ̃EZ, 2003: 442.

25 Respecto de ciertas partidas de dinero concedidas a los infantes Pedro y Juan para poder emplearlas en la guerra contra los granadinos (con el permiso del pontífice Juan XXII). GOÑI GAZTAMBIDE, 1958: 284-286. Por su parte, Jaime II de Aragón intentó apropiarse de la recaudación de esa décima papal para su empresa sarda. FÀBREGA GRAU, 1963: 45. ORTI, 2005: 251-252.

26 Ejemplos citados por LADERO QUESADA, 1993: 206-207. Según este autor, se canceló el cobro del tercer año. Al parecer, en 1312 Clemente V volvió a conceder a Fernando IV una décima para la empresa granadina que quedó sin efecto por la muerte del monarca. GOÑI GAZTAMBIDE, 1958: 282.

27 Alfonso XI llegó a pedir décimas de hasta diez años, pero acortando el cobro a cinco, de forma similar a la petición formulada por Pedro el Ceremonioso en 1340 respecto a una décima de seis años, a percibir durante tres años.

$28 \mathrm{Al}$ respecto, véase BAYDAL, 2009. 
primera décima concedida a ese monarca y la última de ese siglo que estuvo justificada por la guerra contra el infiel.

Por otra parte, durante este periodo de tiempo, la monarquía aragonesa apeló al clero para conseguir su ayuda por motivos de diversa índole; además del subsidio de 1294 — por los gastos de la embajada enviada a Bonifacio VIII para preparar la paz de Anagni-, siguieron otros en 1310 - para pagar deudas derivadas de la campaña de Almería —, 1313 — para hacer frente a más deudas del rey y pagar las dotes matrimoniales de las infantas María y Constanza - 1322 — conquista de Cerdeña - 1331 — guerra de Granaday 1339 - guerra del Estrecho-. La aportación económica de esos subsidios fue siempre in crescendo: 5.000 libras en 1294, 10.000 en 1313 y 1322, y 12.000 en 1331 y 1339 , al menos por lo que respecta a las sumas comprometidas por el clero de la Tarraconense ${ }^{29}$. Los subsidios anotados aquí fueron aprobados en el marco de diferentes concilios provinciales. A partir de entonces, la actividad conciliar en ese sentido iba casi a desaparecer, abriéndose un largo paréntesis que alcanza, de hecho, hasta la época Trastámara ${ }^{30}$.

A diferencia de lo expuesto para la Corona de Aragón, en Castilla no parece que esas asambleas eclesiásticas desempeñaran ningún papel en las ayudas concedidas a los monarcas. La única vez en que se alude de forma explícita a concilios provinciales es a propósito de la décima de 1310, cuando el papa Clemente $\mathrm{V}$ ordenó la entrega al rey de la décima ya recogida para la empresa granadina, y concedió una nueva décima por un año, pero antes mandó celebrar concilios provinciales para que el episcopado castellano pudiera ser consultado al respecto ${ }^{31}$. Años antes (1303), los prelados de la provincia Tarraconense reunidos en Lleida habían realizado una votación sobre si aceptaban o no la imposición de una décima ${ }^{32}$. Por muy inaudito que parezca este episodio, no lo sería tanto atendiendo a cómo se habían gestionado otras contribuciones

29 A raíz de la creación, en 1318, del arzobispado de Zaragoza — segregado del de Tarragona-, cada provincia abordó esas ayudas al rey por separado.

30 El Ceremonioso lo intentó en 1357, ya en el marco de la guerra contra Castilla, pero sin resultado. ZUNZUNEGUI, 1958. El subsidio de 1382 - para sufragar el passatge a Cerdeña del infante Juan-, fue fruto de gestiones realizadas con diferentes cabildos por separado.

31 GOÑI GAZTAMBIDE, 1958: 277. LINEHAN, 1975: 215. El único concilio provincial conocido para ese año es el celebrado en Salamanca (del clero de la provincia compostelana) y no parece que se debatiera ninguna cuestión de tipo fiscal. SÁNCHEZ HERRERO, 1982: 113.

32 Un total de 46 eclesiásticos votó a favor de contribuir en la décima frente a una mayoría de 131 que votó en sentido opuesto. VINCKE, 1936: 55 (doc. $\mathrm{n}^{\circ}$ 99). Quienes votaron en contra fueron mayoritariamente eclesiásticos de categorías inferiores, mientras que los obispos y la mayoría de abades se pronunciaron favorablemente, lo que fue utilizado por el monarca para intentar influir en la decisión final del papa; pese a la embajada enviada a Roma por el sector discordante, Benedicto XI dio su aprobación, aunque murió antes de que los documentos solemnes pudieran ser debidamente autentificados. Véase FÀBREGA GRAU, 1963: 19-22. 
del clero. El hecho cierto es que, a partir de entonces, la opinión del clero ya no sería más tenida en cuenta en las sucesivas décimas decretadas por el papado.

Como se ha visto, la guerra contra el infiel ocupa un lugar destacado hasta mediados del siglo XIV, sobre todo en Castilla, donde, para financiar las campañas contra los musulmanes, se utilizaron otros recursos de la Iglesia, como las tercias reales, que también tenían que ser autorizadas por el papado, así como las limosnas provenientes de la predicación de la cruzada. De hecho, cruzada, tercias y décimas son conceptos que solían ir asociados - por ejemplo, en las concesiones papales de 1329 y $1340^{33}$ - lo que más bien crea dificultades a la hora de intentar discernir entre lo que pagaría el clero y lo que provendría de las limosnas de los laicos, o entre lo que debía ingresar el físco regio y lo que pudo ser transferido a la corte pontificia.

\section{SEGUNDA MITAD DEL SIGLO XIV: LAS DÉCIMAS SERIADAS}

En la Corona de Aragón, a partir de mediados del siglo XIV hubo un motivo recurrente para seguir negociando la concesión de nuevas décimas, como fue la problemática conservación del dominio sobre Cerdeña, que el monarca aragonés tenía en feudo del papa. El ciclo se inicia con la otorgada en 1349 por Clemente $\mathrm{VI}^{34}$ y tuvo continuidad en las subsiguientes concesiones de décimas hasta la década de 1370; tras el impasse propiciado por el Cisma y por la apropiación de las rentas de la Cámara Apostólica por parte de Pedro el Ceremonioso, siguió otro periodo intensivo de concesión de décimas hasta la época del Interregno y de la consiguiente entronización de los Trastámaras ${ }^{35}$.

Los periodos de disfrute de esas décimas acostumbraron a ser de dos o tres años. El periodo más largo se registra a propósito de la décima concedida en $1393^{36}$, que quedó interrumpida por la muerte de Juan I, aunque fue recuperada a partir de 1400, siguiendo mientras tanto con la colecta de otras décimas autorizadas por el papado. El hecho es que durante los reinados de Juan I y de Martín I prácticamente no hubo ningún año que quedara libre de recaudación decimal ${ }^{37}$, lo que las convirtió de facto en una fuente de ingresos regular. El

33 LADERO QUESADA, 1993: 199-200.

34 Véase SÁNCHEZ MARTÍNEZ, 1994-1995. En Francia, la recaudación de este impuesto se intensificó durante la primera mitad de aquel siglo para entrar, a partir de entonces, en declive, según CAUSSE, 1988: 353.

35 Véase MORELLÓ BAGET, 2011a.

36 La concesión al rey aragonés se acompañó de la cesión de otras fuentes de renta eclesiástica (primicias, causas pías inciertas y usuras).

37 Como de costumbre, había establecidas dos pagas anuales, que en esta época de finales del siglo XIV se hacían corresponder con la festividad de San Juan Bautista y con la de Todos los Santos. 
monarca aragonés fue su principal beneficiario, como perceptor de todo o de la mayor parte del producto de esa recaudación; la parte reservada por el papado, generalmente un tercio de la colecta, debía ser transferida directamente a la Cámara Apostólica para subvenir a los gastos del Cisma. Ahora bien, como ya se ha puesto de manifiesto en otros trabajos, la recaudación de esos impuestos se utilizó más que nada para pagar las deudas de la monarquía las cantidades adelantadas por algunos financieros-, y para diversos gastos de la corte - incluidas asignaciones monetarias a favor de algunas reinas-, y no tanto para el gasto militar de Cerdeña $\mathrm{o}$ —en algún momento más puntual-, del de Sicilia.

Por lo que respecta a Castilla, después de la décima obtenida por Pedro I en 1352 por seis años — con una tercera parte reservada al papado-, existe un vacío que afecta a las dos siguientes décadas ${ }^{38}$. Tenemos que esperar hasta 1381 para encontrar una sucesión ininterrumpida de ese impuesto. Juan I se benefició de cuatro décimas consecutivas: las dos primeras bienales, seguida de una trienal y otra por 10 años. Esas décimas pudieron ser cedidas íntegramente, como la otorgada al mismo monarca en 1385, o solo en parte: así, la de 1388 fue repartida mitad para el rey, mitad para el papa. En cuanto a los motivos que condujeron a la concesión de esas décimas, casi ningún historiador consultado da información precisa, excepto para la de $1388^{39}$.

En el caso de las décimas no solía indicarse la cantidad que debía ser recaudada, lo que no suponía desconocer el posible montante en función de otras colectas anteriores. Por lo que respecta a la Corona de Aragón, podemos aportar algunos datos: ya en 1309, se consideraba que la décima no ascendía anualmente a más de $18 \mathrm{mil} \mathrm{lb}$. barc. $(32.727 \mathrm{fl} \text {. })^{40}$. Tanto en 1329 como en 1340, su rendimiento anual se estimaba cercana a las 20 mil lb., mientras que los cálculos realizados con respecto a las décimas del periodo 1349-1354 - ya después de la Peste Negra-, vuelven a situar la cifra en algo menos de 18 $\mathrm{mil}^{41}$. En 1375, era el propio rey, Pedro el Ceremonioso, quien hacía una estimación de la recaudación decimal en torno a $30 \mathrm{mil} \mathrm{fl}$. anuales $(16.500$

38 Tal vacío, ¿debería ser achacado a la falta de fuentes? Resulta extraño si se compara con las dinámicas de los reinos vecinos, no solo de la Corona de Aragón, sino también de Portugal, donde se registran décimas bastante seriadas a lo largo del siglo XIV - teóricamente justificadas por la guerra contra el infiel-, por lo menos hasta 1377, que es el periodo estudiado por M. Farelo, 2013.

39 Se vincularía a la defensa de las fortalezas fronterizas con Granada, según MONTES, 2009: 657. Y si damos crédito a la misma autora, parece que en años anteriores se concedió una décima por cuatro años que no comenzó a ser recaudada hasta que el monarca Juan I decidió emplearla —en 1384 - en la guerra contra Portugal. MONTES, 2009: 658-659.

40 FÀBREGA GRAU, 1963: 34. BAYDAL, 2009.

41 SÁNCHEZ MARTÍNEZ, 1994-1995: 1292. MORELLÓ BAGET, 2015a: 95. 
lb. $)^{42}$. A nivel diocesano, tampoco presentaba dificultades saber cuál podía ser la recaudación decimal, al menos aproximadamente, partiendo de la suma de las tasas beneficiales en el marco de la respectiva circunscripción ${ }^{43}$.

El cobro de tales décimas excluía, en principio, la petición de otras ayudas eclesiásticas durante el tiempo que durase la imposición ${ }^{44}$. No obstante, Pedro el Ceremonioso iba a hacer caso omiso a ese precepto, pues a lo largo de su extenso reinado se registran numerosos subsidios pedidos al clero, ya fuera por la cuestión de Cerdeña - en 1354, por el viaje del rey a esa isla, y en 1382 por el que tenía planeado el infante Juan-, también por los sucesivos matrimonios del rey $(1347,1349)$, por la caballería y matrimonio del infante Juan (1371), por el matrimonio de algunas infantas $(1372,1375)$ y por la coronación de la reina Sibila (1381) y, ya por último, por la celebración de los cincuenta años de su reinado, esto es, con motivo del jubileo de $1386^{45}$. Los subsidios de la década de 1380 se corresponden con la etapa de apropiación de las rentas de la Cámara Apostólica, durante la cual el monarca aragonés, como es lógico, no pudo seguir disfrutando de nuevas concesiones de décimas $^{46}$. Durante los reinados de Juan I y Martín I, coincidiendo con otra etapa de intensificación en la recaudación de décimas, se hicieron otras demandas de subsidios: en 1388 - para sufragar los gastos sostenidos por la monarquía en pro de la Iglesia - , en 1392 — por el matrimonio de la infanta Juana-, en 1395 y 1397 — por la defensa de Cerdeña ${ }^{47}$ —. Esas demandas fueron estipuladas por cuantías bastantes modestas — de 12, 15 o 18 mil fl.—, bastante por

42 Car les dècimes no munten cascun any segons que trobam sinó a XXX mil florins, ACA, C, reg. 1460, ff. 13v-14r. Respecto de esa décima, E. Tello, 2015, ha calculado que se llegó a recaudar — sin contar los atrasos-, un total de 1.154.119,2 sueldos para todo el trienio, incluida la parte de reserva papal, de donde podemos colegir un rendimiento anual de casi 35.000 fl., exactamente $34.973,3 \mathrm{fl}$.

43 En 1424 el concilio de la Tarraconense mandó recopilar las valoraciones que habían estado vigentes hasta entonces para cada obispado, unas valoraciones que se corresponden en gran medida con las utilizadas durante la segunda mitad del siglo XIV, por lo menos desde 1358. Ello estaría relacionado con la operación de reducción de las tasas, a la que me referiré luego.

44 A propósito de la décima bienal de 1345, el papa Clemente VI lanzaba una advertencia a Pedro el Ceremonioso para que no pudiera exigir o pedir ningún subsidio mientras durase la recaudación del impuesto decimal, sin que ello comportase derogar otras ayudas concedidas con anterioridad. De hecho, ya la décima bienal de 1324 había sido concedida a cambio de no poder solicitar, por parte de Jaime II, ninguna otra ayuda al clero durante un periodo igual de dos años.

45 Según información extraída, una vez más, de SÁNCHEZ MARTÍNEZ, 2011.

46 El obispo y cabildo de Lleida condicionaron su aceptación al subsidio de 1382 a cambio, entre otras cosas, de que no se les pidiera ningún otro durante cinco años, ya fuera invocando la cuestión de Cerdeña o por necesidades de la Cámara Apostólica confiscada; por su parte, el obispo de Huesca puso como condición un límite temporal de dos años.

47 Los dos anotados para 1395 y 1397 no implicaron gravámenes directos sobre el clero, pues en realidad fueron cantidades otorgadas por Benedicto XIII a favor, respectivamente, de Juan I y de Martín I, y consignadas sobre los ingresos de la colectoría de Aragón. 
debajo, pues, del rendimiento obtenido de las décimas de esa época ${ }^{48}$. Ahora bien, algunos de esos subsidios pudieron ser cargados, en todo o en parte, sobre los vasallos de la Iglesia, lo que parece ser el caso, por lo menos, de todos aquellos que se refieren a las coronaciones de los reyes y a los matrimonios de las infantas, como, de hecho, iba a quedar regulado en $1419^{49}$.

En lo tocante a Castilla, no hay constancia de ningún subsidio pedido al clero hasta los últimos años del siglo XIV — más o menos coincidiendo con el cese en la recaudación de las décimas-, y por diversas razones, entre las cuales destacaría el conflicto con Portugal y la cuestión del Cisma — para el pago de embajadas-, aunque también se pudo recurrir a ciertos empréstitos ${ }^{50}$. Al parecer, el subsidio de 1398 fue solicitado por Enrique III en una junta de prelados reunida en Salamanca ${ }^{51}$. La situación creada por el Cisma —en periodo de sustracción de obediencia-, podría haber propiciado que la monarquía se viera impelida a pedir una ayuda extraordinaria en el marco de una asamblea del clero, si es que nunca se había hecho antes, ya que las fuentes castellanas no parecen ser muy explícitas al respecto.

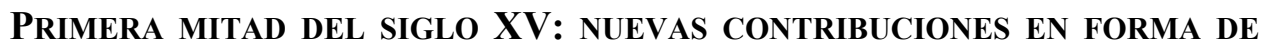 SUBSIDIOS}

A partir de la segunda década del siglo XV, se abrió un nuevo periodo en el que el subsidio pasó a ser la única vía de contribución extraordinaria del clero, tanto en la Corona de Aragón como en Castilla. Y es que, de acuerdo con las nuevas disposiciones aprobadas en el concilio de Constanza ${ }^{52}$, las únicas décimas legitimadas eran las que tendrían carácter universal, lo que supuso poner fin a la sucesión de concesiones particulares a favor de las monar-

48 Según mis cálculos, la recaudación anual de las décimas de esta época se situaba entre las 17-18 mil lb. MORELLÓ BAGET, 2011a: 175. Convertido a la moneda de referencia, serían entre 30.909-32.727 fl., algo por debajo, pues, de la estimación realizada en 1375.

49 En la llamada Transacción de Sant Cugat, donde se estableció la forma como los vasallos de la Iglesia debían contribuir en las demandas de coronatge (tanto de reyes como de reinas) y de maridatge (por el matrimonio de las infantas), revalidando de ese modo una forma de proceder ya establecida de facto.

50 Para hacer frente a las compensaciones debidas al duque de Lancaster, Enrique III solicitó en 1395 que le prestasen cierta cuantía de francos a repartir entre toda la clerecía del reino. Esos préstamos se harían en oro y plata, y pasarían a estar consignados sobre las rentas regias. MONTES, 2009: 660. Los denominados «empréstitos sobre la plata de las iglesias», ya documentados en la década de 1340, tuvieron siempre carácter ocasional; por lo que respecta al siglo XV, son especialmente conocidos los de 1429 y 1474-75. NIETO SORIA, 1994: 33842. ORTEGO RICO, 35 (Madrid, 2012).

51 DÍAZ IBÁÑEZ, 2003: 441.

52 Respecto al alcance de las disposiciones fiscales de este Concilio, véase STUMP, 1989. 
quías. Así, no debe extrañarnos de que no prosperasen algunas peticiones realizadas por Alfonso el Magnánimo al papado, a objeto de conseguir nuevas concesiones de décimas.

En Castilla, podemos contabilizar hasta una docena de subsidios en el periodo comprendido entre 1414 y $1444^{53}$. Los primeros de la serie se relacionan con la cuestión del Cisma, sirviendo, más concretamente, para sufragar los gastos derivados de las legaciones enviadas a Constanza, pero a partir de $1430 \mathrm{su}$ principal razón de ser o, mejor dicho, su pretexto fue la guerra contra los nazaríes. Todos esos subsidios fueron fruto, presuntamente, de negociaciones bilaterales Monarquía-Papado, esto es, sin pasar por ninguna asamblea del clero.

En un lapso de tiempo similar tenemos registrados seis subsidios concedidos a Alfonso el Magnánimo. Los tres primeros fueron aprobados por el clero reunido en asambleas conciliares (Lleida-1418, Tarragona-1424, Tortosa1429), siempre teniendo como telón de fondo el asunto del Cisma, aún pendiente de resolución en los territorios del monarca aragonés; la época coincide, además, con una nueva etapa de apropiación regia de las rentas ordinarias de la Cámara Apostólica. Los celebrados en Lleida y Tortosa tuvieron carácter interprovincial, pues también contaron con la participación del clero aragonés y con la presencia de los legados pontificios enviados por el papa Martín $\mathrm{V}$, que actuaron como correa transmisora de las promesas de ayuda realizadas por el papa a favor del monarca Trastámara. Así pues, los eclesiásticos pudieron pronunciarse ante esas nuevas demandas, consiguiendo, en algún caso, obtener rebajas sobre las cantidades postuladas inicialmente ${ }^{54}$. Aunque la época se corresponde con el auge, en el contexto internacional, del conciliarismo, ya existía, como ya hemos visto, una tradición conciliar que venía de lejos. Sin embargo, una vez normalizadas las relaciones con la Santa Sede, se impuso la negociación bilateral Monarquía-Papado, como queda corroborado por los dos siguientes subsidios de 1433 y 1443, ambos destinados a financiar la guerra de Italia. En cambio, el de 1451 fue establecido para poner fin a ciertas cuestiones de orden interno ${ }^{55}$.

53 NIETO, 1994: 325-326. VILLARROEL GONZÁLEZ, 2013: 331 y 334. DÍAZ IBÁÑEZ, 2003: 442-443. TORIJA, 2012: 219. La ayuda otorgada en forma de limosna por el papa Nicolás V en 1448 no tendría nada que ver con un subsidio sobre el clero, por lo que no lo incluyo aquí.

54 El subsidio de 1418 fue una imposición en toda regla del legado. En cambio, el de 1424 fue convenido dar por el clero de la Tarraconense «graciosamente» y no por obligación. También el de 1429 fue otorgado del mismo modo al papa y luego asignado por el legado Pedro de Foix al monarca Trastámara. Los legados enviados a la Corona de Aragón también solicitaron otras cantidades en concepto de derechos de procuración. Para más datos, véase MORELLÓ BAGET, 2011b: 257-259. Sobre el desarrollo de esas reuniones, véase GROHE, 1991.

55 Concretamente, a cambio de la revocación del edicto fiscal de 1448, por el cual Alfonso $\mathrm{V}$ pretendió imponer un gravoso gravamen sobre los bienes traspasados a la Iglesia en 
Los subsidios de la nueva época Trastámara tuvieron estipuladas cantidades cada vez más elevadas, que alcanzaron un punto máximo, precisamente, con los más de 185.000 fl. otorgados en 1451; según Küchler, fue el subsidio más cuantioso que nunca había prometido dar la Iglesia a la monarquía, a tal punto que en algunas diócesis iba a dejar secuelas por largo tiempo ${ }^{56}$.

Los subsidios del clero castellano - en una época en la que la moneda de referencia también era el florín de Aragón-, acostumbraron a estar fijados en 100 mil fl. ${ }^{57}$ Haciendo un somero balance comparativo, podríamos ver que durante el periodo comprendido entre 1418-1451, la contribución del clero de Castilla vía subsidios extraordinarios se situaría por encima de los $700.000 \mathrm{fl}$. y algo menos (665.400 fl.) en la Corona de Aragón. Sin embargo, no podemos pasar por alto el desigual potencial contributivo de uno y otro reino, aspecto que podrá ser corroborado luego a propósito del nivel de renta sometida a tributación ${ }^{58}$.

\section{Segunda mitad del siglo XV: el retorno a las décimas y su reconversión en subsidios}

En la Corona de Aragón, después del subsidio de 1451 no hubo ningún otro otorgado a la monarquía, aunque no tenemos muy claro si tal interrupción derivaría de la promesa hecha por el Magnánimo de no imponer a la Iglesia nuevas contribuciones separadamente de las que pudiesen recaer sobre los demás súbditos de cada reino ${ }^{59}$. Lo cierto es que, a partir de entonces, se abrió una nueva etapa en la que la ausencia de subsidios dejó paso al pago, una vez más, de décimas.

concepto de derecho de amortización, lo que fue considerado por el estamento eclesiástico como altamente lesivo para sus intereses. KÜCHLER, 1997: 313. De hecho, el Magnánimo pudo inspirarse en lo que estaba sucediendo en Castilla, donde las Cortes de Valladolid de 1447 establecieron un nuevo impuesto de amortización. Véase NIETO SORIA, 1994: 109.

56 Por lo menos en la de Barcelona, donde el consiguiente endeudamiento provocado por el pago de ese subsidio no pudo ser liquidado del todo hasta la segunda década del siglo XVI. Véase BAUCELLS, 1984: 19-25.

57 Suma equivalente a 27 millones de maravedís. Téngase en cuenta, por otro lado, que los ingresos ordinarios procedentes de las tercias reales oscilaban (1428-1429) entre 3 y 3,5 millones.

58 En Castilla, el número de diócesis más que duplicaba (32) al de la Corona de Aragón (14). Por otra parte, en Castilla el número de beneficios eclesiásticos podría situarse hasta un máximo de 15 mil, mientras que en la Corona de Aragón estaría en poco más de 10 mil.

59 Esa interpretación se fundamenta en lo dispuesto en la concordia incluida en la bula Regis pacifici del 25 de enero de 1451. KÜCHLER, 1997: 322. El texto de dicha concordia - se trata de la famosa Bula de oro-, utiliza, por lo que respecta al punto que nos interesa, diferentes palabras (petición, demanda, imposición o exacción), pero en ningún caso el término subsidio. 
El primer papa Borja, Calixto III, fue el responsable del retorno a la décima - la decretada por él para financiar la cruzada contra los conquistadores turcos de Constantinopla-, cuya consideración de décima universal entraba dentro del cliché establecido en Constanza ${ }^{60}$. Una vez más, Castilla iba a apartarse del régimen general, acordando pagar un subsidio que en parte pudo destinarse a la guerra contra el sultanato nazarí. Posteriores décimas otorgadas por el papado serían sistemáticamente conmutadas por subsidios, tanto durante la guerra contra Granada, cuando los Reyes Católicos consiguieron que las concesiones papales se equipararan a la cruzada contra los turcos, como más tarde, a propósito de las campañas realizadas contra los moros de Berbería. De hecho, una concordia firmada por Fernando e Isabel en 1495 preveía reconvertir todas las décimas en subsidios por una determinada cantidad global (100.000 fl.a.), confirmando, de esa manera, algo que ya venía siendo habitual a lo largo de la segunda mitad del siglo $X^{61}$. En cambio, en la Corona de Aragón no se documenta ningún tipo de conversión (¿habría sido posible a tenor del pacto suscrito en 1451?), de manera que cada nueva décima obtenida tuvo que ser satisfecha de la forma acostumbrada.

Los estudiosos castellanos entienden que la opción por el subsidio suponía una contribución menor que en el caso de una décima; así, el monto habitual de $100.000 \mathrm{fl}$. implicaría aplicar un tipo de gravamen del 5\% ${ }^{62}$. Por tanto, la conmutación conllevaría una más que significativa disminución de la carga fiscal, si es que únicamente se tiene en cuenta ese factor ${ }^{63}$. En cuanto a los eclesiásticos de la Corona de Aragón, quizás la única manera de poder incidir en el grado de presión fiscal fue, como veremos luego, intentando obtener reducciones sobre las tasas utilizadas como base imponible.

En Castilla, el fenómeno apuntado de la reconversión de las décimas en subsidios podría relacionarse con la aparición en torno a 1460 —en la época, justamente, de la décima calixtina-, de las juntas o congregaciones del cle$\mathrm{ro}^{64}$. Las principales funciones de esas asambleas fueron la defensa de las

60 Sobre la recaudación de la décima de 1455-1457, véase, además de KÜCHLER, 1997: 236-259, el trabajo de NAVARRO SORNÍ, 2003.

61 GARCÍA-VILLOSLADA, 1980, vol. III-1: 201, n 134 . Al parecer, fueron los cabildos quienes propiciaron ese acuerdo. Véase FERNÁNDEZ DE CÓRDOVA MIRALLES, 2005: 672 .

62 Ciertamente, hubo otros subsidios establecidos por cantidades algo mayores, pero siempre por debajo del 10\%; el de 1494, por una cuantía de 115.000 fl., tendría estipulado un gravamen situado en torno al $8 \%$.

63 M. Vázquez parece aportar un ejemplo en contrario, aunque, por otra parte, da por sentado que tales conversiones llevaban implícitas una moderación. VÁZQUEZ BERTOMEU, 2002a: 480.

${ }^{64}$ M. Vázquez documenta congregaciones del clero a partir de 1457. VÁZQUEZ BERTOMEU, 2002a: 470. Otros autores, siguiendo a Tarsicio de Azcona, sostienen que la primera asamblea del clero en otorgar una contribución fue la de 1462 en Valladolid. Así lo recogía 
libertades eclesiásticas así como la negociación de las obligaciones fiscales con la Corona, más en concreto, la repartición y colecta de los referidos subsidios ${ }^{65}$. También en la Corona de Aragón se observa una situación análoga respecto de la serie de «concilios» o parlamentos celebrados en la provincia Tarraconense, siendo asambleas participadas, más que por los obispos - muchos de ellos ausentes de sus sedes-, por los representantes de los cabildos catedralicios ${ }^{66}$. El clero de las diócesis catalanas siguió esgrimiendo la tradicional defensa de sus libertades y franquezas frente a lo que consideraba un nivel excesivo de contribución, pero, que sepamos, nunca se decantó por la «fórmula» de reconversión adoptada en Castilla ${ }^{67}$.

Es evidente, por otra parte, que la aportación de la Iglesia castellana a la hacienda real sería mucho más elevada que la de su homóloga aragonesa. Las contabilidades de finales de siglo no dejan lugar a duda sobre cuál de los dos reinos contribuía más en términos absolutos. Catalán ha calculado lo que ambos territorios aportaron a la hacienda regia entre 1495 y 1503 bajo el concepto de subsidios/décimas: un $86,3 \%$ de Castilla frente a tan solo un $13,7 \%$ de la Corona de Aragón ${ }^{68}$. Durante ese periodo, el pago de subsidios siguió un ritmo prácticamente anual ${ }^{69}$. Este ciclo fiscal tuvo continuidad en la época de Carlos V, cuando, para seguir financiando la guerra contra el turco, se optó por la implantación de nuevos gravámenes proporcionales (cuartas, dobles cuartas y medios frutos), también susceptibles de ser reconvertidos en subsidios a un tanto alzado.

SÁNCHEZ HERRERO, 1981: 128. Por su parte, J. M. Nieto documenta una reunión en Salamanca de representantes del clero de algunas diócesis para presentar agravios al rey contra la décima calixtina. NIETO SORIA, 1994; 334.

65 Entre los historiadores castellanos existen discrepancias entre aquellos que consideran a esas asambleas como meros instrumentos al servicio de la monarquía y aquellos otros que tienden a destacar más su papel opositor.

66 Los historiadores de la Iglesia dudan a la hora de calificar esas reuniones de verdaderos concilios, pues apenas legislaron sobre temas internos de la Iglesia, girando la mayoría de cuestiones tratadas en torno a temas contributivos. Madurell dio a conocer diversas asambleas de ese tipo entre 1455-1469 a partir de fuentes conservadas en el Archivo de Protocolos de Barcelona.

67 Tan aferrados estaban a la tradición que, a raíz del posterior intento de imponer una «cuarta» (1523), no cejaron en el empeño hasta conseguir que quedase conmutada por una décima, lo que sin duda había de conllevar una carga fiscal más soportable.

68 CATALÁN, 2013: 357. Esos porcentajes no son muy diferentes si se añaden otros conceptos tributarios, como la cruzada y los jubileos, que fueron incorporados a partir de 1475 como gracia espiritual que se ganaba a cambio de visitar cualquier iglesia catedral y de ofrecer una limosna. GARCÍA-VILLOSLADA, 1980, tomo III-1: 192. CATALÁN, 2013: 355.

69 Contando a partir de 1494, hay registrado (según los datos suministrados por E. Torija) un subsidio cada año, excepto para el bienio 1498-1499. Por lo que respecta a la Corona de Aragón, durante el decenio 1494-1504 hay documentadas varias décimas alternando con años -en principio-, no contributivos. 


\section{LA TASACIÓN DE LAS RENTAS ECLESIÁSTICAS Y EL REPARTO DE LOS SUBSIDIOS}

Cualquier gravamen establecido de forma proporcional implicaba realizar antes una valoración de las rentas beneficiales, como ya es posible constatar a propósito de la vigésima de $1229^{70}$. Más pronto que tarde, sería necesario recopilar las tasas fiscales asignadas a cada beneficio para usar como patrón de referencia en posteriores colectas ${ }^{71}$, esto es, mediante la confección de libros - en el marco de cada diócesis-, con el inventario de todos los beneficios existentes, anotando las pagas debidas por cada titular y/o lo que hubiera ya pagado ${ }^{72}$. Los primeros libros de tasas conservados en el archivo de los reyes de Aragón (ACA) son de principios del siglo XIV ${ }^{73}$, pero solo comienzan a ser abundantes a partir de mediados del trescientos, esto es, coincidiendo con la época de las décimas seriadas. En cambio, para Castilla, las fuentes archivísticas disponibles son muy escasas y al parecer inexistentes para esos primeros siglos; eso ha llevado a algún historiador a postular que nunca se llegó a realizar una tasación de las rentas beneficiales ${ }^{74}$. En mi opinión, es difícil imaginar que las rentas del clero castellano no fueran tasadas a efectos

70 Respecto a cierto requerimiento hecho al abad de Sant Benet de Bages para que declarase las rentas de su monasterio con vistas a poder efectuar el repartimiento de la vigésima instituida in subsidio Maioricarum. GUAL VILÀ, 2003: 747-748.

71 En principio, había dos opciones a la hora de deducir la cantidad a pagar por cada beneficio: a priori sobre una estimación de los ingresos anuales, es decir, usando una tasa ya fijada de antemano, o bien a posteriori sobre el valor real de lo percibido, realizando, pues, una valoración actualizada de las rentas percibidas. VÁZQUEZ BERTOMEU, 2002b: 63. La segunda opción más bien sería aplicable a los nuevos beneficios incorporados a los inventarios fiscales, sobre todo por lo que respecta a las capellanías de nueva fundación.

72 Las Rationes decimarum de 1279-80 solo registran las cuotas de contribución anual, presuntamente obtenidas de una valoración fiscal previa de las rentas beneficiales. Posteriormente, se alude a la tasa antigua, y ya en 1330 se registra una petición del monarca aragonés para que se llevara a cabo una nueva tasación de las rentas más acorde con el valor que tendrían en ese momento, lo que no fue autorizado por el papa. GOÑI GAZTAMBIDE, 1958: 306-307.

73 Por ahora, el registro más antiguo de recaudación decimal que tenemos localizado se halla en el Archivo de la catedral de Barcelona; se trata del manuscrito titulado «Decima Catalonie», relativo a la décima sexenal de 1297. Los primeros registros conservados en el ACA (RP, MR) lo son en relación con la décima de 1305.

74 Se ha afirmado que el cobro de la décima en Castilla se hizo particularmente difícil, porque aún no había sido tasada, y que el cómputo fiscal encargado por Clemente VI no llegó a realizarse. GARCÍA-VILLOSLADA, 1982, vol. II-2: 395. También se decía —en base a una posterior súplica a Clemente VII de parte de la Iglesia de Calahorra-, que Pedro el Cruel había tasado excesivamente los beneficios de la diócesis calagurritense, y que presuntamente sería la primera vez que esa tasación se hacía. ZUNZUNEGUI, 1942: 242. Con todo, una carta papal de 1354 deja bastante claro que la orden de proceder a la estimación de las rentas de cara a la colecta de la décima sexenal de Pedro I concernía únicamente a aquellos beneficios que aún no estuvieran tasados. ZUNZUNEGUI, 1970: 44 (doc. nº 51). De algún modo, podría interpretarse que todos los beneficios restantes sí lo estaban. 
fiscales atendiendo a la sucesión de décimas que ya hemos comentado con anterioridad. De hecho, hay informaciones que dan cuenta de la utilización de libros de tasas, pese a no haberse conservado ninguno para esa época ${ }^{75}$.

También los subsidios pasaron a ser repartidos en función de las tasas decimales — de ello ya da fe el aprobado en el concilio de Horta de 131376 pudiendo aplicar, según el caso, otros porcentajes de contribución; así, el subsidio otorgado a Pedro el Ceremonioso en 1339 comportó establecer dos pagas, cada una de 1 sueldo por libra (5\%), como si se tratase de una décima; de hecho, debía ser recaudado de acuerdo con las tasas de la décima antigua ${ }^{77}$. A partir de entonces, numerosas referencias documentales ponen de manifiesto un alto grado de asimilación entre ambos tipos de prestación ${ }^{78}$. Los subsidios del siglo XV siguieron siendo contribuciones establecidas por tasa ${ }^{79}$, lo que da pie a una equiparación de facto con las décimas.

Tratándose de subsidios a un tanto alzado, primero de todo era necesario distribuir la suma global entre las diferentes diócesis. Durante una primera época fueron los arzobispos, como máximos dignatarios de cada provincia, los principales organizadores de esas reparticiones ${ }^{80}$. Cada obispado se encargaría luego de los repartimientos al por menor, en los que comenzaron a jugar un rol cada vez mayor los cabildos catedralicios; no en balde, los colectores de esas exacciones solían ser canónigos.

En Castilla se han dado a conocer diferentes repartos de subsidios realizados a lo largo del siglo XV (1430, 1482 y 1494), con sumas variables para cada diócesis dependiendo del total a recaudar, o de la inclusión o no de las

75 Así, por ejemplo, en 1371 el cabildo catedralicio de Cuenca se dirigía al rey indicando cómo tradicionalmente, cuando los reyes exigían un subsidio para la lucha contra los musulmanes, solían demandar de toda la clerecía diocesana una determinada cantidad según la tasa recogida en los libros antiguos. DÍAZ IBÁÑEZ, 2003: 441. En 1384, Juan I escribía al arzobispo de Sevilla reclamándole el pago de la décima según la tasación antigua. MONTES, 2009: 658-659.

76 Dicho subsidio fue tasado secundum taxacionem decime per ipsos iam solute. VINCKE, 1936: 119 (doc. $\left.n^{\circ} 181\right)$.

77 Sobre cómo se gestionó este subsidio. Véase MORELLÓ BAGET, 2015a.

78 Así, por ejemplo, el subsidio de 1388 debía ser satisfecho ab illis qui decima vel aliud subsidium loco decime minime solvere consueverunt proporcionabiliter juxta facultates suorum reddituum ecclesiasticorum, ADB, RC, vol. 43, f. $124 \mathrm{r}-\mathrm{v}$.

79 KÜCHLER, 1997: 233.

80 Por ejemplo, las cantidades del subsidio de 1286 fueron tasadas por el arzobispo de Tarragona, como también se hace patente a propósito del compartimiento efectuado en 1339, sin incluir, en este caso, a las diócesis aragonesas ya segregadas de la provincia. Del repartimiento de las sumas adjudicadas a cada diócesis se ocupaba cada obispo, como queda atestiguado en el caso de Tortosa en relación con el subsidio de 1322. VINCKE, 1936: 293-294 (doc. $\left.n^{\circ} 406\right)$. 
órdenes militares ${ }^{81}$. Por su parte, Torija ha dado a conocer el reparto al por menor del clero urbano de Toledo en el subsidio de 1482, esto es, mostrando la cuantificación de renta anual y la cuota de contribución de cada clérigo.

El procedimiento sería tal como lo explica Catalán para época moderna ${ }^{82}$ : una vez conocida la cantidad global que se debía pagar, se efectuaba un primer prorrateo según la facultad de cada obispado; posteriormente, la asamblea diocesana procedía a la distribución interna entre los arciprestazgos mediante una simple regla de tres entre la riqueza global de la diócesis y la cuantía del impuesto; el resultante era el tanto por ciento que se debía aplicar a la facultad de cada parroquia, expresado en x maravedís por cada mil de facultad.

Para pagar el subsidio, y mientras no se procedía al establecimiento entre el clero diocesano de tallas proporcionales - «per solidum et libram» o de «sueldo por libra»-, los obispos pudieron realizar anticipos a cuenta de las cantidades asignadas a sus diócesis, sobre todo cuando la necesidad era apremiante ${ }^{83}$. Así, más de un «préstamo» realizado por los obispos, o por sus cabildos, podrían estar motivados por circunstancias de ese tipo; ciertamente, habría mucho por indagar en este terreno.

Otras veces, para poder atender al pago de las exigencias regias, el clero se vio impelido a contratar préstamos, cuyos capitales luego intentaría devolver a partir del establecimiento de tallas. Ya de cara al pago del subsidio acordado en 1429, Alfonso el Magnánimo dio permiso al clero de Cataluña, Valencia y Mallorca, excepción hecha del de Aragón, para poder vender censales (deuda a largo plazo) con el fin de pagar los 60.000 fl. destinados a la corona ${ }^{84}$. Fue este un expediente al que el clero volvería a recurrir en otras ocasiones, por ejemplo, a propósito del subsidio de 1443, cuando incluso pudo hacerse extensivo a algunas diócesis aragonesas ${ }^{85}$.

Entre las fuentes de esa época seguimos encontrando, para la Corona de Aragón, libros de tasas beneficiales, de cara a la recaudación de las contribuciones extraordinarias impuestas al clero. Muchos de esos libros se localizan en los archivos diocesanos y/o capitulares, lo cual da idea del uso preferente que hicieron de ellos los cabildos catedralicios como principales ejecutores de los repartimientos realizados entre el clero diocesano ${ }^{86}$. En Castilla hay con-

81 LADERO QUESADA, 1982: 194.

82 CATALÁN, 2013: 366.

83 Un solo ejemplo bastaría: en 1323, a propósito del subsidio concedido al infante Alfonso para la conquista de Cerdeña — en el marco del concilio provincial de Tarragona celebrado un año antes - , Jaime II urgía al obispo de Barcelona a adelantar la suma correspondiente a él y al clero de su diócesis. VINCKE, 1936: 285 (doc. $\mathrm{n}^{\circ} 395$ ).

${ }^{84}$ MORELLÓ BAGET, 2011b: 259.

85 MORELLÓ BAGET, 2015b.

86 En cambio, en el ACA solo se conservan registros relativos al subsidio de 1443, algunos de ellos relativos al cómputo de los veros valores. Volveré a referirme a ello dentro de poco. 
servados, ya por lo que respecta a finales del siglo $\mathrm{XV}$, algunos libros de tasaciones bajo la denominación, precisamente, de Libros de subsidio ${ }^{87}$. Al respecto, se pueden distinguir dos tipos de registros, unas veces conteniendo la tasa máxima a cotizar por cada contribuyente y otras veces la relación de lo que cada uno debía pagar, en forma, pues, de padrón de tributación ${ }^{88}$.

A lo largo de la primera mitad del siglo XV, hay documentadas, en la Corona de Aragón, varias operaciones de modificación de las tasas beneficiales, me refiero a las reducciones practicadas en la provincia Cesaraugustana (1407), con el beneplácito de Benedicto XIII, y años más tarde en la Tarraconense (1424), con la aprobación de Martín V, en uno y otro caso permitiendo rebajar las tasas a la mitad ${ }^{89}$. Vino después una campaña de valoración integral de las rentas de todos los beneficios, de cara a la confección de los llamados veros valores, para el pago, en primera instancia, del subsidio establecido en 1443. Ello dio pie a la elaboración de manifiestos recogiendo las declaraciones de cada clérigo beneficiado, tanto de los ingresos como de los gastos soportados, a partir de los cuales se fueron confeccionando registros más sumarios con las tasas adjudicadas a cada uno ${ }^{90}$. Con todo, el primer papa Borja autorizó a realizar otra retasación general, que debía entrar en vigor una vez efectuado el pago de la décima según las valoraciones ya realizadas ${ }^{11}$. Por su parte, el clero de la Tarraconense siguió reclamando una nueva reducción de las tasas como la que ya se había hecho en $1424^{92}$. Todo ello habría dado pie a una reutilización de los libros de veros valores en función de distintas revisiones ${ }^{93}$.

87 Ladero llevó a cabo el análisis de tres libros de subsidio conservados en la catedral de Sevilla (1491, 1494 y 1503). LADERO QUESADA, 1982: 198. Por su parte, Vázquez Bertomeu ha analizado varios Libros relativos al arzobispado de Santiago de Compostela, siendo el más antiguo uno de 1485-88, pero existen noticias a la existencia de Libros de subsidio en otras diócesis, presuntamente conteniendo las tasaciones que sirvieron como referencia de los repartimientos. VÁZQUEZ BERTOMEU, 2002b: 79.

88 VÁZQUEZ BERTOMEU, 2002b: 77.

89 El subsidio de 1433 fue satisfecho - a razón de 2 sueldos por libra en seis pagas durante tres años-, secundum taxacionem decime modernam sive noviter reductam, ACB, secc. Dècima, subsidi i excussat, Libro del subcolector Marc Garcès (1434-1435).

90 Véase MORELLÓ BAGET, 2015b.

91 Así, la décima por él decretada tendría que ser recaudada íntegramente, conforme a los veros valores. NAVARRO SORNÍ, 2003: 196.

92 Considerando que las valoraciones practicadas en la década de 1440 habían sido excesivas. MADURELL, 1947: 109-110. En todo caso, la norma pasaba por ceñirse a las tasaciones contenidas en los libros de veros valores, según se indica a propósito de cierta derrama efectuada en 1460 .

93 También las diócesis aragonesas hicieron uso de las nuevas valoraciones; así, la décima satisfecha por el clero diocesano de Huesca en 1489 lo fue secundum verum valorem. Poco después se llevó a cabo una revisión general de los veros valores de la provincia eclesiástica de Zaragoza, de acuerdo con lo prescrito en una bula papal de Inocencio VIII. Una de las 
En Castilla, hay registrada una operación similar en la misma época de la cruzada contra el turco — en torno a 1457 - en relación con la décima que fue luego reconvertida en subsidio ${ }^{94}$. Esa actualización fue tenida en cuenta a propósito de los subsidios pedidos para financiar la guerra de Granada, pero la necesidad de llevar a cabo nuevas averiguaciones de los veros valores iba a plantearse a lo largo también de la siguiente centuria ${ }^{95}$.

Con los datos disponibles para el siglo XV, se puede hacer una evaluación de las rentas eclesiásticas que, en el caso de Castilla, se ha situado (Ladero) en torno a 2.000.000 fl.a. El cómputo realizado en la Corona de Aragón a raíz de la citada operación de revalorización arroja una cifra algo inferior a los 700.000 fl. ${ }^{96}$ Así pues, según esos datos, la renta eclesiástica de la Corona de Aragón equivaldría al $35 \%$ de la de Castilla, lo que resulta bastante plausible como indicador del diferente potencial economico-fiscal del clero de uno y otro reino.

\section{CONCLUSIÓN}

En lo que se ha venido llamando la Revolución fiscal de la Baja Edad Media habría que otorgar un lugar destacado a la aparición, difusión y consolidación de los impuestos sobre las rentas eclesiásticas, en la medida en la que también se fueron incorporando a los nuevos sistemas impositivos estatales. Aunque las primeras exacciones de este tipo parecen retrotraerse a la época de la segunda y tercera cruzadas, no cabe duda de que su generalización se produjo a lo largo del siglo XIII. Para financiar las campañas militares al sur de la Península, tanto los reyes castellanos como los aragoneses recurrieron

tareas encomendadas a los comisarios era que «videant et revideant adque diligenter recognoscant libros de taxis antiquis et signanter de taxis noviter ultimo ordinaria auctoritate factis, quos una cum libris de taxis modernioribus debent periesse habere continue providendis et revidendis adque examinandis dictis taxis et valoribus beneficiorum taxandorum», ACZ, Libro de la collecta de la décima y tachacio de los fruytos eclesiásticos del abadiado de Montearagón (1491), s.f.

94 Declarando veritatem sive modernum, verum et certum valorem, según figura en el preámbulo del manuscrito que dio a conocer Ángel Barrios, 1991, referente al obispado abulense.

95 Los subsidios de la guerra de conquista de Granada fueron distribuidos sobre los valores computados en 1457, como señala OLLERO PINA, 2011: 118. También M. Vázquez registra pesquisas realizadas en el ámbito del arzobispado compostelano sobre los verdaderos valores de los beneficios. VÁZQUEZ BERTOMEU, 2002a: 479. Ya para el siglo XVI, una de las primeras alusiones al valor verdadero de los beneficios se registra a propósito de la imposición, en 1523, de la cuarta. GARCÍA-VILLOSLADA, 1980, vol. III-1: 202. Por su parte, Catalán se refiere a averiguaciones realizadas en años posteriores.

96 Si son de fiar las sumas anotadas en ACM, Subsidios no 16503 (referente al de 1443) por un total de $381.812,8 \mathrm{lb} .=694.205 \mathrm{fl}$. 
en un principio a las décimas generales — las destinadas a Tierra Santa-, más tarde sustituidas por concesiones papales específicas. Sin embargo, mientras en Castilla esos impuestos siguieron muy vinculados a la guerra contra los musulmanes, las décimas de la Corona de Aragón pasaron a ser utilizadas, al menos en teoría, en otras necesidades militares vinculadas al problemático dominio de Cerdeña, convirtiéndose, además, en una fuente de ingresos casi regular para la corona, excepción hecha del periodo de la apropiación de la Cámara Apostólica. En Castilla, en cambio, parece existir un vacío considerable entre las décimas seriadas de la primera mitad y las de finales de esa centuria.

Durante los siglos XIII-XIV, también se observa un incremento de los subsidios pedidos directamente al clero por motivos diversos, no únicamente por la lucha contra los musulmanes, sino también para otras necesidades, a veces consideradas más perentorias, de ahí que ciertas prestaciones adoptaran la forma de subsidio-préstamo. Durante la primera mitad del siglo XIV, en la Corona de Aragón fue usual que esas ayudas fueran aprobadas en el marco de los concilios provinciales, no así en Castilla, donde apenas hay constancia de tal práctica. Los monarcas aragoneses no se abstuvieron de realizar otras peticiones de dinero para pagar dispendios de la Casa Real (coronaciones, matrimonios de infantas...) que, no obstante, quedaron circunscritas al ámbito de los contribuyentes laicos vasallos de la Iglesia.

A raíz de las limitaciones impuestas por el concilio general de Constanza, la demanda de subsidios devino casi la única vía permitida para seguir obteniendo contribuciones extraordinarias del clero, y mientras en la Corona de Aragón volvemos a encontrar, en un primer momento, ayudas concedidas «graciosamente» en el marco de algunas asambleas eclesiásticas, pronto se convirtieron en una contribución obligatoria y sujeta, igual que las décimas, a una autorización papal. Así pues, los Trastámaras aragoneses acabaron recurriendo, igual que sus parientes castellanos, a la negociación bilateral monarquía-papado.

Tras la reimplantación de las décimas en la segunda mitad del siglo XV, en Castilla se optó por la reconversión sistemática en subsidios, fenómeno que no parece ser ajeno a la aparición, en esa misma época, de las congregaciones del clero, cuyo cometido debía ser tanto instrumental - en la repartición de las sumas establecidas-, como político - en la defensa de las libertades eclesiásticas-. Ahora bien, su poder de influencia política sería limitado por la menor presencia de prelados y el mayor protagonismo adquirido por los representantes de los cabildos en la gestión de esas cargas fisca${ }_{1 e s}{ }^{97}$. Y es que, al tener que lidiar con unas contribuciones previamente autorizadas por el papado, el margen de maniobra de esas asambleas sería

97 En Castilla, se señala una ausencia de representación episcopal en las asambleas del clero celebradas a partir de 1505, según PERRONE, 2008: 4. 
bastante reducido, más aún en la Corona de Aragón, donde el clero siguió estando sujeto al pago de las tradicionales décimas.

Como se ha visto para la Corona de Aragón, subsidios y décimas operaban sobre la misma base imponible, esto es, tomando como referente las tasas beneficiales. A lo largo del siglo $\mathrm{XV}$, esas tasas fueron sometidas, en un primer momento, a reducciones a la mitad y, más tarde, a actualizaciones de cara al cómputo de los veros valores, lo que serviría tanto para el pago de los subsidios como de las décimas u otros gravámenes proporcionales implementados más tarde. Los subsidios, desde nuestra óptica, presentan una doble faceta: como impuestos de repartición entre obispados y como impuestos de cuota, ya que debían ser recaudados en el seno de cada diócesis en función de la distinta valoración fiscal asignada a cada beneficio, según lo anotado en los correspondientes libros de tasas. En Castilla, la conversión de las décimas en subsidios no es impedimento para poder seguir considerando a estos como impuestos sobre la renta ${ }^{98}$.

Subsidios y décimas no fueron sino dos vías diferentes para alcanzar un mismo fin, que no sería otro que el de conseguir gravar las rentas de los eclesiásticos — en su forma beneficial—, de cara a su incorporación a la fiscalidad estatal. El resultado final de ese largo proceso iniciado en el siglo XIII fue convertir unas contribuciones extraordinarias en casi ordinarias y por obligación, sirviendo para reforzar la sumisión del clero como contribuyente del estado ${ }^{99}$.

\section{BiblografíA}

Arranz Guzmán, Ana, «El episcopado y la guerra contra el infiel en las Cortes de la Castilla Trastámara», en José Manuel Nieto Soria (dir.), La monarquía como conflicto en la corona castellano-leonesa (c.1230-1504), Madrid, Sílex, 2006: 253-298.

Barrios, Ángel, Libro de los veros valores del obispado de Ávila (1458), Ávila, Diputación Provincial/Caja de Ahorros de Ávila, 1991.

Baucells i Reig, Josep, «El subsidi eclesiàstic de l'any 1451», en La Corona d'Aragona e il Mediterraneo: aspetti e problema comuni da Alfonso il Magnanimo a Ferdinando il Cattolico (1416-1516). IX Congresso di Storia della Corona d'Aragona (Napoli, 11-15 aprile 1973), vol. III, Palermo, Accademia di Scienze Lettere e Arti, 1984: 11-33.

98 Según el punto de vista expresado por algunos modernistas; Catalán, por ejemplo, considera al subsidio como un auténtico impuesto sobre la renta. CATALÁN, 2013: 365.

99 El largo proceso evolutivo someramente descrito aquí acabó desembocando en la implantación - a finales del siglo XVI-, de las llamadas Tres Gracias (cruzada, subsidio y excusado). Con todo, el tema del consentimiento del clero siguió estando latente en los debates del siglo XVII. Al respecto, véase FORTEA PÉREZ, 2015. 
Baydal, Vicent, «Tan grans messions. La financiación de la cruzada de Jaime II de Aragón contra Almería en 1309», Medievalismo, 19 (Madrid, 2009): 57-154.

Carocci, Sandro y Collavini, Simone M., «The Costs of States: Politics and Exactions in the Christian West (Sixth to Fifteenth Centuries)», en John Hudson y Ana Rodríguez (eds.), Diverging Paths? The shapes of power and institutions in Medieval Christendom and Islam, Leiden/Boston, Brill, 2014: 125-158.

Catalán, Elena, «De la décima al subsidio. Fiscalidad eclesiástica en la diócesis de Calahorra y La Calzada (siglos XV-XVI)», en Jordi Morelló Baget (ed.), Financiar el reino terrenal. La contribución de la Iglesia a finales de la Edad Media (siglos XIII-XVI), Barcelona, IMF-CSIC, 2013: 345-377.

Causse, Bernard, Église, finance et royauté. La floraison des dècimes dans la France du Moyen Âge, 2 vols., Paris, Aux Amateurs de Livres, 1988.

De la Mardière-Chevreau, Christophe y Chevreau, Emmanuelle, «La dîme saladine», en La religion et l'impôt. Actes du colloque de Clermont-Ferrand, 6 et 7 avril 2006 / La Revue, vol. 1, 2012: 23-28.

Díaz Ibáñez, Jorge, Iglesia, sociedad y poder en Castilla. El obispado de Cuenca en la Edad Media (siglos XII-XV), Cuenca, Alfonsípolis, 2003.

Fàbrega Grau, Àngel, «La ayuda económica de la Iglesia a Jaime II de Aragón para la conquista de Cerdeña», Anthologica Annua, XI (Roma, 1963): 11-46.

Farelo, Mario, «Payer au roi et au pape. Les décimes pontificales imposées au clergue portugais pendant l'époque avignonnaise», en Jordi Morelló Baget (ed.), Financiar el reino terrenal. La contribución de la Iglesia a finales de la Edad Media (siglos XIII-XVI), Barcelona, IMF-CSIC, 2013: 55-106.

Fernández de Córdova Miralles, Álvaro, Alejandro VI y los Reyes Católicos. Relaciones político-eclesiásticas (1492-1503), Roma, Pontificia Universitas Sanctae Crucis, 2005.

Fortea Pérez, José Ignacio, «¿Pagar y obedecer? La Iglesia y el clero ante el físco regio en Francia y en España en tiempos de guerra (1635-1659)», en Massimo Carlo Giannini (ed.), Fiscalità e religione nell'Europa cattolica. Idee, linguaggi e pratiche (secoli XIV-XIX), Roma, Viella, 2015: 111-166.

Freedman, Paul, «Two letters of Pope Honorius III on the collection of ecclesiastical revenues in Spain», en Church, law and society in Catalonia, 900-1500, Aldershot, Ashgate/Variorum, 1994: 37-40.

García-Villoslada, Ricardo (dir.), Historia de la Iglesia en España, vols. II-2 ${ }^{\circ}$ y III$1^{\circ}$, Madrid, Biblioteca de Autores Cristianos, 1980 y 1982.

Goñi Gaztambide, José, Historia de la bula de la cruzada en España, Vitoria, Editorial del Seminario, 1958.

Grohe, Johannes, Die Synoden im Bereich der Krone Aragón von 1418-1429, Paderborn, Schöningh, 1991.

Gual Vilà, Valentí, Justícia i terra: la documentació de l'Arxiu de Poblet (Armari II), Valls, Cossetània, 2003.

Küchler, Winfried, Les finances de la Corona d'Aragó al segle XV (regnats d'Alfons V $i$ Joan II), València, Edicions Alfons el Magnànim, 1997. 
Ladero Quesada, Miguel Ángel, La Hacienda Real de Castilla en el siglo XV, La Laguna, Universidad, 1973.

Ladero Quesada, Miguel Ángel, «Renta eclesiástica en la Castilla del siglo XV», en El siglo XV en Castilla. Fuentes de renta y política fiscal, Barcelona, Ariel, 1982: 190-212.

Ladero Quesada, Miguel Ángel, Fiscalidad y poder real en Castilla (1252-1369), Madrid, Universidad Complutense, 1993.

Ladero Quesada, Miguel Ángel, «Estructuras y políticas fiscales en la Baja Edad Media», Edad Media. Revista de historia, 2 (Valladolid, 1999): 113-150.

Ladero Quesada, Miguel Ángel, «Lo antiguo y lo nuevo de la investigación sobre fiscalidad y poder político en la Baja Edad Media hispánica», en Estados y mercados financieros en el Occidente cristiano (siglos XIII-XVI). Actas de la XLI Semana de Estudios Medievales de Estella. 15 al 18 de julio de 2014), Pamplona, Gobierno de Navarra, 2015: 13-54.

Linehan, Peter, La iglesia española y el papado en el siglo XIII, Salamanca, Universidad Pontificia, 1975.

Madurell Marimón, José Ma , «Concilios tarraconenses (1455-69)», Analecta Sacra Tarraconensia, XX (1947): 103-149.

Mansilla, Demetrio, La documentación pontificia hasta Inocencio III (965-1216), Roma, Instituto Español de Estudios Eclesiásticos, 1955.

Montes Romero-Camacho, Isabel, «Poder real y fiscalidad eclesiástica en los orígenes del estado moderno. La contribución de la Iglesia sevillana a la Hacienda Real de Castilla en tiempos de los primeros Trastámara (1369-1420)», en Castilla y el mundo feudal. Homenaje al profesor Julio Valdeón, vol. II, Valladolid, Junta de Castilla y León/Universidad de Valladolid, 2009: 649-664.

Morelló Baget, Jordi, «La contribución de la Iglesia a las arcas del rey: a propósito de la recaudación de las décimas en la Corona de Aragón a finales del siglo XIV y principios del XV», en Denis Menjot y Manuel Sánchez Martínez (eds.), El dinero de Dios. Iglesia y fiscalidad en el Occidente Medieval (siglos XIII-XV), Madrid, Instituto de Estudios Fiscales, 2011a: 167-190.

Morelló Baget, Jordi, «Las relaciones monarquía-papado en la etapa final del Gran Cisma y la sucesión de dos modelos distintos de transferencia fiscal en la Corona de Aragón», en Ángel Sesma Muñoz (dir.), La Corona de Aragón en el centro de su historia 1410-1412. El Interregno y el Compromiso de Caspe (Zaragoza y Alcañiz 24, 25 y 26 de noviembre de 2010), Zaragoza, Gobierno de Aragón, 2011b: 233-263.

Morelló Baget, Jordi, «La contribución del clero de la Corona de Aragón a la guerra del Estrecho (década de 1340) y sus consecuencias fiscales», en Daniel Baloup y Manuel Sánchez Martínez (eds.), Partir en croisade à la fin du Moyen Âge. Financement et logistique, Toulouse, Presses Universitaires du Midi, 2015a: 81-116.

Morelló Baget, Jordi, «La contabilización de los "veros valores" en la Corona de Aragón y la gestión del subsidio eclesiástico de 1443 (a partir de las cuentas de un notario barcelonés)», en Thierry Pécout (dir.), De l'autel à l'écritoire: aux origines des comptabilités princières en Occident (XII-XIV siècle), Paris, De Boccard, 2015b: 207-239. 
Navarro Sorní, Miguel, Calixto III Borja y Alfonso el Magnánimo frente a la cruzada, València, Ajuntament, 2003.

Nieto Soria, José Manuel, Iglesia y génesis del estado moderno en Castilla (13691480), Madrid, Complutense, 1994.

Nieto Soria, José Manuel, «Fiscalidad eclesiástica y estado monárquico en la Castilla bajomedieval», en Denis Menjot y Manuel Sánchez Martínez (eds.), El dinero de Dios. Iglesia y fiscalidad en el Occidente Medieval (siglos XIII-XV), Madrid, Instituto de Estudios Fiscales, 2011: 101-113.

Ollero Pina, José Antonio, «La Iglesia de Sevilla y la consolidación de los subsidios (1482-1495)», en Denis Menjot y Manuel Sánchez Martínez (eds.), El dinero de Dios. Iglesia y fiscalidad en el Occidente Medieval (siglos XIII-XV), Madrid, Instituto de Estudios Fiscales, 2011: 115-131.

Ortego Rico, Pablo, «Las riquezas de la Iglesia al servicio del poder monárquico: los empréstitos eclesiásticos en la Castilla del siglo XV», En la España Medieval, 35 (Madrid, 2012): 145-176.

Orti, Pere, «Les alienacions del patrimoni reial i el finançament de la conquesta de Sardenya de 1323-1324», en La Corona Catalanoaragonesa i el seu entorn mediterrani a la baixa Edat Mitjana, Barcelona, IMF-CSIC, 2005: 239-272.

Perrone, Sean, Charles $V$ and the Castilian Assembly of the Clergy: Negotiations for the Ecclesiastical Subsidy, Leiden \& Boston, Brill, 2008.

Rius Serra, José, Rationes decimarum Hispaniae (1279-1280), 2 vol., Barcelona, CSIC, 1946-1947.

Sánchez Herrero, José, «Los concilios provinciales y los sínodos diocesanos españoles (1215-1550)», Quaderni catanesi di Studi Classici e Medievali, 5 (Catania, 1981): 113-181 y 7 (Catania, 1982): 111-197.

Sánchez Martínez, Manuel, «Fiscalidad pontificia y finanzas reales en Cataluña a mediados del s.XIV: Las décimas de 1349, 1351 y 1354», Estudis castellonencs, 6 (1994-1995): 1277-1296.

Sánchez Martínez, Manuel, «La participación de la Iglesia de Cataluña en las finanzas regias: los subsidios extraordinarios (1249-1400)», en Denis Menjot y Manuel Sánchez Martínez (eds.), El dinero de Dios. Iglesia y fiscalidad en el Occidente Medieval (siglos XIII-XV), Madrid, Instituto de Estudios Fiscales, 2011: 133-165.

Stump, Phillip H., "The Reform of Papal Taxation at the Council of Constance (1414-1418)», Speculum, 64 (1989): 69-105.

Tello Hernández, Esther, «La contribución eclesiástica a las demandas reales en la Corona de Aragón: la décima de 1375», en V. Muñoz y E. Aznar (coords.), Hacer Historia desde el Medievalismo, San Cristóbal de La Laguna, Universidad de La Laguna, 2015.

Torija Rodríguez, Enrique, «El subsidio eclesiástico para la guerra de Granada (1482-1492). Aportación, ingresos y gastos en el arzobispado de Toledo», Medievalismo, 22 (Madrid, 2012): 217-238.

Vázquez Bertomeu, Mercedes, «La Iglesia de Santiago hacia 1500: el libro I del Subsidio», Compostellanum, 47/3-4 (Santiago de Compostela, 2002a): 439-486.

Vázquez Bertomeu, Mercedes, «Una fuente para el estudio de la geografía eclesiásti- 
ca de Galicia en la Baja Edad Media: las tasaciones del subsidio y la décima», Cuadernos de estudios gallegos, 49/115 (Santiago de Compostela, 2002b): 57-80.

Villarroel González, Óscar, El rey y la Iglesia castellana. Relaciones de poder con Juan II (1406-1454), Madrid, Fundación Areces, 2011: 319-344.

Villarroel González, Óscar, «La tributación de los eclesiásticos castellanos en el siglo XV: entre el rey y el papa», en Jordi Morelló Baget (ed.), Financiar el reino terrenal. La contribución de la Iglesia a finales de la Edad Media (siglos XIII-XVI), Barcelona, IMF-CSIC, 2013: 315-343.

Vincke, Johannes, Documenta selecta mutuas civitatis Arago-Cathalaunicae et ecclesiae relationes illustrantia, Barcelona, Biblioteca Balmes, 1936.

Vincke, Johannes, «Estado e Iglesia en la historia de la Corona de Aragón de los siglos XII, XIII y XIV», VII Congreso de Historia de la Corona de Aragón, vol. 1, Barcelona, Imp. Viuda de Rodríguez Ferran, 1962: 267-285.

Zunzunegui, José, El reino de Navarra y su obispado de Pamplona durante la primera época del Cisma de Occidente, pontificado de Clemente VII de Aviñón (13781394), San Sebastián, Pax, 1942.

Zunzunegui, José, «Para la historia del Concilio Provincial Tarraconense de 1357», Scriptorium Victoriense, 5/2 (1958): 339-343.

Zunzunegui, José, Bulas y Cartas secretas de Inocencio VI (1352-1362), Roma, Instituto Español de Historia Eclesiástica, 1970.

Recibido: 01/12/2015

Aprobado: 21/10/2016 